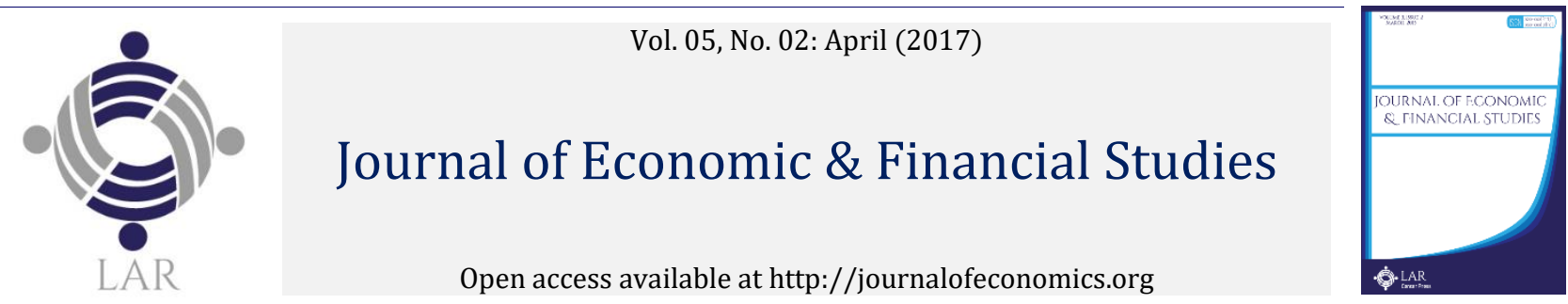

\title{
Nursing manpower and productivity in medical service industry
}

\author{
Jui-Hsiang Wang a, ${ }^{*}$, Chun-Chu Liu ${ }^{b}$ \\ a Department of infection Diseases, Taipei Veterans General Hospital, Hsinchu Branch, Hsinchu, Taiwan. \\ b Graduate School of Business and Operation Management, Chang Jung Christian University, Tainan, Taiwan. \\ ${ }^{*}$ Corresponding author's email address: hemletkimo@gmail.com
}

\begin{abstract}
A R T I C LE I N F O
Received: 03-03-2017

Accepted: 01-04-2017

Available online: 10-04-2017

Keywords:

Assessment models;

Malmquist index;

Medical service industry;

Nursing manpower;

Total factor productivity.

A B S T R A C T

The Malmquist Index (MI) is a bilateral index that can be used to compare the production technology of two economies also as two different time status of one economy. Since, the nurse-to-bed ratio is the standard quantitative indicators of changes in technical efficiency, changes in technology, and total factor productivity in the medical service industry; we explore the link between the nurse-to-bed ratio and three MIs at the industry level using Twainese context. Our results show that the annual average nurseto-bed ratio is inversely related to changes in efficiency in large cities. However, in medium-sized cities, annual changes in the average nurse-to-bed ratio are inversely related to the total factor productivity. We propose four assessment models to assist in the formulation of strategies aimed at improving the quality of care as well as productivity while considering the particulars of individual cities and regions.
\end{abstract}

JEL Classification:

$\mathrm{I} 13, \mathrm{I} 15, \mathrm{I} 18,032$.

(C) 2017 The Authors. This is an open access article under the terms of the Creative Commons Attribution License 4.0, which allows use, distribution and reproduction in any medium, provided the original work is properly cited.

DOI: http://dx.doi.org/10.18533/jefs.v5i02.280

\section{Introduction}

Lack of sufficient medical manpower is a major global policy issue despite decades of attempts to control the problem(Barros, De Menezes, Peypoch, Solonandrasana, \& Vieira, 2008; Conrad, 2009). Increasing healthcare capacity requires the adoption of advanced medical techniques and the efficient use of existing manpower. However, expansion can lead to considerable increases in healthcare revenue as well as costs. Nursing accounts for most personnel-related costs. A low nurse-to-bed ratio can increase efficiency(Farsi \& Filippini, 2005; Herr, 2008); however, a high nurse-to-bed ratio can improve the quality of care(Association, 1997, 2000; Mark, Harless, McCue, \& Xu, 2004). Researchers have yet to fully elucidate how these factors interact to improve medical outcomes as well as profits, thereby allowing sufficient growth to ensure the quality of healthcare services. The fact that expenditures increase over time has prompted hospital managers to establish hospital reimbursement systems to enhance efficiency, adopt new technologies (Burke \& Menachemi, 2004; Nadzam \& Macklis, 2001), and elevate total factor productivity(Glickman \& Peterson, 2009; Tompkins, Higgins, \& Ritter, 2009). Unfortunately, efforts to control healthcare costs often result in compromised healthcare quality.

Numerous researchers have investigated the relationship between medical personnel and the efficiency of hospitals in the provision of healthcare. The environmental and cultural conditions make a different change (Harrison, Henriksen, \& Hughes, 2007; Singer et al., 2009). Researchers have applied efficiency estimation techniques such as data envelopment analysis (DEA) to measure efficiency at the hospital level(Sikka, Luke, \& Ozcan, 2009). However, at the industry level, most research has focused on productivity. 
The purpose of this research was to examine the 10-year period following the National Health Insurance employing for the 2nd decades. The study involves four stages of work. First, we used the National Health Insurance database to calculate the nurse-to-bed ratio in 22 counties and cities in Taiwan, i.e., at the industry level rather than at the hospital level. The index nurse-to-bed ratio at the industrial level indicates the scale of the medical service provider, remoteness of the facility, the investment by the government, different environment, and cultures. Second, we measured the three Malmquist indices (MIs): technical efficiency change (EFFCH), technological change (TC), and total factor productivity (TFP)(Färe, Grosskopf, Norris, \& Zhang, 1994; Nishimizu \& Page, 1982). Third, we conducted statistical analysis of Taiwan's medical service industry between 2005 and 2014 (10 years) to identify correlations between the change in annual average nurse-to-bed ratio and efficiency, technological process change, and total productivity. Finally, based on the nurse-to-bed ratio and TFP, we divided the medical service industry in those 22 counties and cities into four groups. The study reveals the dynamic interactions of these indices and their implications.

\section{Data and methodology}

We employed a retrospective longitudinal-sectional observational research design. We divided the total number of nurses by the total number of beds in every county and city in Taiwan to obtain the nurse-to-bed ratio for each year. Analysis of the three MIs (EFFCH, TC, TFP) was conducted using four inputs and two outputs selected as per the DEA/Malmquist index method, which is a non-parametric frontier estimation approach.

\section{$2.1 \quad$ Collected data}

Data was obtained from the National Health Insurance database for the period 2005-2014. As recommended by Ozcan (2008), we selected four inputs: the number of doctors, the number of nurses, the number of other medical staff, and the number of beds. We selected two outputs: outpatient visits and several admissions. Ccharacteristics of the 22 counties and cities surveyed are listed in Table 1.

Table 1: Features of collected data

\begin{tabular}{|c|c|c|c|}
\hline Scale & Numbers of beds & Nos. & Counties and cities \\
\hline Large & $\begin{array}{l}\text { More than } 10,000 \\
\text { beds, }\end{array}$ & 6 & $\begin{array}{l}\text { Taipei City (DMU: L01), Kaohsiung City (L02), Taichung City (L03), } \\
\text { New Taipei City (L04), Taoyuan City (L05), Tainan City (L06) }\end{array}$ \\
\hline $\begin{array}{l}\text { Mediu } \\
\mathrm{m}\end{array}$ & $\begin{array}{l}\text { More than } 1000 \text { beds, } \\
\text { less than } 10,000 \text { beds }\end{array}$ & 13 & $\begin{array}{l}\text { Changhua County (M01), Pingtung County (M02), Hualien County } \\
\text { (M03), Yilan County (M04), Chiayi City (M05), Yunlin County (M06), } \\
\text { Miaoli County (M07), Chiayi County (M08), Nantou County (M09), } \\
\text { Keelung City (M10), Hsinchu City (M11), Hsinchu County (M12), } \\
\text { Taitung County (M13) }\end{array}$ \\
\hline Small & Less than 1000 beds & 3 & Penghu County (S01), Kinmen County (S02), Lianjiang County (S03) \\
\hline Total & & 22 & \\
\hline
\end{tabular}

Table 2 lists the variables addressed in the empirical analysis. The nurse-to-bed ratio is the measure of the loading of nurse manpower. The variable "NTB-A" refers to the average nurse-to-bed ratio each year in that city over a period of 10 years. The variable "NTB-AC" refers to the average change in the nurse-to-bed ratio each year. DEA/Malmquist index analysis was conducted using MaxDEA, and statistical analysis was performed using SPSS. According to the definitions of variables listed in table 2 , we got summary statistics of the variable as listed in table 3 and table 4.

Table 2: Definitions of variables

\begin{tabular}{|c|c|c|c|}
\hline & Variable name & Unit & Variable description \\
\hline \multirow[t]{4}{*}{ Input variables } & Number of doctors & Persons & Number of full-time doctors \\
\hline & Number of Nurses & Persons & Number of full-time nurses \\
\hline & $\begin{array}{l}\text { Number of other } \\
\text { medical staffs }\end{array}$ & Persons & $\begin{array}{l}\text { Number of full-time medical staff other than doctors } \\
\text { and nurses }\end{array}$ \\
\hline & Number of beds & Numbers & Number of beds \\
\hline \multirow{2}{*}{ Output variables } & Outpatient visits & Numbers & Number of outpatient visits and emergency visits \\
\hline & Admissions & Numbers & Number of times admitted \\
\hline variable & NTB-A & Ratio & Annual average nurse-to-bed ratio \\
\hline variable & NTB-AC & Ratio & $\begin{array}{l}\text { Average annual change in nurse-to-bed ratio from one } \\
\text { year to the next }\end{array}$ \\
\hline
\end{tabular}


Table 3: Summary statistics of the variables

\begin{tabular}{llrrr}
\hline Variable name & Unit & Average & STD & Range \\
\hline Number of doctors & Persons & 2515 & 3087 & $15 \sim 12813$ \\
Number of Nurses & Persons & 4922 & 5454 & $18 \sim 21831$ \\
Number of other & Persons & 1669 & 1898 & $10 \sim 7885$ \\
medical staffs & & & & \\
Number of beds & Numbers & 7076 & 6990 & $36 \sim 24899$ \\
Outpatient visits & Numbers & 15498365 & 15379498 & $123153 \sim 59598623$ \\
Admissions & Numbers & 137799 & 122821 & $1086 \sim 460626$ \\
NTB-A & Ratio & & & \\
NTB-AC & Ratio & & & \\
\hline
\end{tabular}

Table 4: The nurse-to-bed ratio in each cities/counties between 2005 and 2014

\begin{tabular}{lllllllllllll}
\hline NTB & 2005 & 2006 & 2007 & 2008 & 2009 & 2010 & 2011 & 2012 & 2013 & 2014 & NTB-A & NTB-AC \\
\hline L01 & 0.815 & 0.831 & 0.829 & 0.838 & 0.854 & 0.851 & 0.855 & 0.861 & 0.888 & 0.877 & 0.850 & 1.008 \\
L02 & 0.638 & 0.631 & 0.654 & 0.685 & 0.702 & 0.736 & 0.767 & 0.794 & 0.816 & 0.824 & 0.725 & 1.029 \\
L03 & 0.638 & 0.633 & 0.652 & 0.669 & 0.672 & 0.694 & 0.702 & 0.726 & 0.746 & 0.734 & 0.687 & 1.016 \\
L04 & 0.624 & 0.668 & 0.667 & 0.679 & 0.693 & 0.704 & 0.703 & 0.715 & 0.749 & 0.719 & 0.692 & 1.016 \\
L05 & 0.572 & 0.590 & 0.628 & 0.654 & 0.671 & 0.672 & 0.688 & 0.714 & 0.723 & 0.732 & 0.664 & 1.028 \\
L06 & 0.611 & 0.622 & 0.639 & 0.652 & 0.669 & 0.703 & 0.740 & 0.817 & 0.853 & 0.845 & 0.715 & 1.037 \\
M01 & 0.687 & 0.653 & 0.702 & 0.667 & 0.691 & 0.697 & 0.708 & 0.738 & 0.752 & 0.769 & 0.706 & 1.013 \\
M02 & 0.574 & 0.588 & 0.614 & 0.625 & 0.649 & 0.642 & 0.661 & 0.642 & 0.666 & 0.696 & 0.636 & 1.022 \\
M03 & 0.482 & 0.494 & 0.499 & 0.497 & 0.514 & 0.507 & 0.499 & 0.508 & 0.507 & 0.519 & 0.502 & 1.009 \\
M04 & 0.507 & 0.508 & 0.523 & 0.551 & 0.574 & 0.574 & 0.577 & 0.604 & 0.623 & 0.687 & 0.573 & 1.035 \\
M05 & 0.583 & 0.581 & 0.592 & 0.665 & 0.670 & 0.661 & 0.661 & 0.700 & 0.714 & 0.748 & 0.657 & 1.029 \\
M06 & 0.568 & 0.583 & 0.605 & 0.621 & 0.619 & 0.619 & 0.646 & 0.645 & 0.672 & 0.700 & 0.628 & 1.024 \\
M07 & 0.465 & 0.495 & 0.490 & 0.461 & 0.472 & 0.469 & 0.488 & 0.509 & 0.552 & 0.547 & 0.495 & 1.019 \\
M08 & 0.602 & 0.613 & 0.620 & 0.630 & 0.660 & 0.686 & 0.689 & 0.680 & 0.697 & 0.726 & 0.660 & 1.021 \\
M09 & 0.509 & 0.504 & 0.511 & 0.524 & 0.542 & 0.536 & 0.555 & 0.557 & 0.572 & 0.559 & 0.537 & 1.011 \\
M10 & 0.544 & 0.553 & 0.552 & 0.567 & 0.583 & 0.594 & 0.583 & 0.580 & 0.584 & 0.598 & 0.574 & 1.011 \\
M11 & 0.698 & 0.719 & 0.718 & 0.804 & 0.851 & 0.869 & 0.869 & 0.898 & 0.924 & 0.910 & 0.826 & 1.031 \\
M12 & 0.540 & 0.526 & 0.539 & 0.536 & 0.526 & 0.512 & 0.549 & 0.523 & 0.549 & 0.551 & 0.535 & 1.003 \\
M13 & 0.627 & 0.661 & 0.651 & 0.643 & 0.638 & 0.655 & 0.649 & 0.668 & 0.709 & 0.706 & 0.661 & 1.014 \\
S01 & 0.541 & 0.537 & 0.539 & 0.575 & 0.608 & 0.597 & 0.594 & 0.599 & 0.589 & 0.574 & 0.575 & 1.007 \\
S02 & 0.324 & 0.348 & 0.441 & 0.493 & 0.650 & 0.639 & 0.658 & 0.654 & 0.637 & 0.417 & 0.526 & 1.046 \\
S03 & 0.409 & 0.455 & 0.426 & 0.556 & 0.583 & 0.490 & 0.455 & 0.455 & 0.436 & 0.436 & 0.470 & 1.015 \\
\hline
\end{tabular}

\subsection{Malmquist index analysis}

The Malmquist Index (MI) (Malmquist, 1953) can be used to assess changes in total factor productivity in a given period. The MI is obtained by multiplying EFFCHby TC. We multiplied the distance function of EFFCH and TC to acquire the distance function of the Malmquist index as follows:

$$
\begin{gathered}
\text { Malmquist index }(\mathrm{MI})=\frac{d_{i}^{t}\left(x_{t}, y_{t}\right)}{d_{i}^{S}\left(x_{s}, y_{s}\right)}\left[\frac{d_{i}^{s}\left(x_{s}, y_{s}\right)}{d_{i}^{t}\left(x_{s}, y_{s}\right)} \times \frac{d_{i}^{S}\left(x_{t}, y_{t}\right)}{d_{i}^{t}\left(x_{t}, y_{t}\right)}\right]^{1 / 2} \\
=\left[\frac{d_{i}^{S}\left(x_{t}, y_{t}\right)}{d_{i}^{S}\left(x_{s}, y_{s}\right)} \times \frac{d_{i}^{t}\left(x_{t}, y_{t}\right)}{d_{i}^{t}\left(x_{s}, y_{s}\right)}\right]^{1 / 2}
\end{gathered}
$$

A change in technical efficiency is also referred to as catch-up effect. In other words, it is the extent to which the technical efficiency of a decision-making unit (DMU) improves or declines. Technological change (also known as innovation effect or frontier-shift effect) reflects changes in the frontier between the two periods. As shown in Eq. (1), the Malmquist index comprises four distance functions: dis (xs, ys), dit (xt, yt), dit (xs, ys), dis (xt, yt). Specifically, dis (xs, ys) and dit (xt, yt) measure the distance from an observation unit (DMU) to the efficiency frontier. When the Malmquist index $>1$, it indicates an increase in TFP from $\mathrm{S}$ to $\mathrm{T}$. When the Malmquist index $=$ 1 , it indicates that the TFP is constant. When the Malmquist index $<1$, it indicates a decrease in TFP. Table 5 lists the correlations among the three MIs, NTB-A, and NTB-AC. 
Table 5: Correlations among three MIs, NTB-A, and NTB-AC

\begin{tabular}{lrrrrrr}
\hline & DMU & EFFCH & TC & MI & NTB-A & NTB-AC \\
\hline Kaohsiung City & L02 & 0.979 & 0.994 & 0.974 & 0.850 & 1.008 \\
Hualien County & M03 & 1.014 & 0.960 & 0.973 & 0.687 & 1.016 \\
Keelung City & M10 & 1.009 & 0.962 & 0.971 & 0.715 & 1.037 \\
Chiayi City & M05 & 0.993 & 0.991 & 0.985 & 0.725 & 1.029 \\
Chiayi County & M08 & 1.001 & 0.980 & 0.981 & 0.574 & 1.011 \\
Kinmen County & S02 & 1 & 1.027 & 1.027 & 0.826 & 1.031 \\
Lianjiang County & S03 & 1 & 0.954 & 0.954 & 0.660 & 1.021 \\
Miaoli County & M07 & 1.010 & 0.984 & 0.994 & 0.692 & 1.016 \\
Nantou County & M09 & 1.012 & 0.978 & 0.990 & 0.664 & 1.028 \\
Penghu County & S01 & 0.982 & 1.019 & 1.001 & 0.535 & 1.003 \\
Pingtung County & M02 & 1 & 0.989 & 0.989 & 0.573 & 1.035 \\
Taipei City & L01 & 1.018 & 0.987 & 1.005 & 0.496 & 1.019 \\
Taitung County & M13 & 1.004 & 0.989 & 0.993 & 0.706 & 1.013 \\
Tainan City & L06 & 1.003 & 0.982 & 0.985 & 0.537 & 1.011 \\
Taichung City & L03 & 0.999 & 0.991 & 0.990 & 0.628 & 1.024 \\
Taoyuan City & L05 & 1.020 & 0.977 & 0.997 & 0.657 & 1.029 \\
New Taipei City & L04 & 1 & 0.979 & 0.979 & 0.636 & 1.022 \\
Hsinchu City & M11 & 1.006 & 0.990 & 0.996 & 0.575 & 1.007 \\
Hsinchu County & M12 & 1.023 & 0.981 & 1.003 & 0.502 & 1.009 \\
Yilan County & M04 & 1.003 & 0.982 & 0.985 & 0.661 & 1.014 \\
Yunlin County & M06 & 1 & 0.963 & 0.963 & 0.526 & 1.046 \\
Changhua County & M01 & 1.006 & 0.983 & 0.989 & 0.470 & 1.015 \\
Mean & & 1.004 & 0.984 & 0.987 & 0.632 & 1.020 \\
\hline & & & & & & \\
\hline
\end{tabular}

\subsection{Classification and models}

As shown in Table 5, we classified the 22 counties and cities according to scale and calculated the correlations among the five variables to clarify the relationship between TFP and nurse-to-bed ratio. We then divided the 22 counties and cities into four quadrants based on the axes of the mean TFP and mean nurse-to-bed ratio. The analysis was conducted using the four assessment models in Figure 1.

Figure 1: Models used in analysis of TFP and NTB in various cities

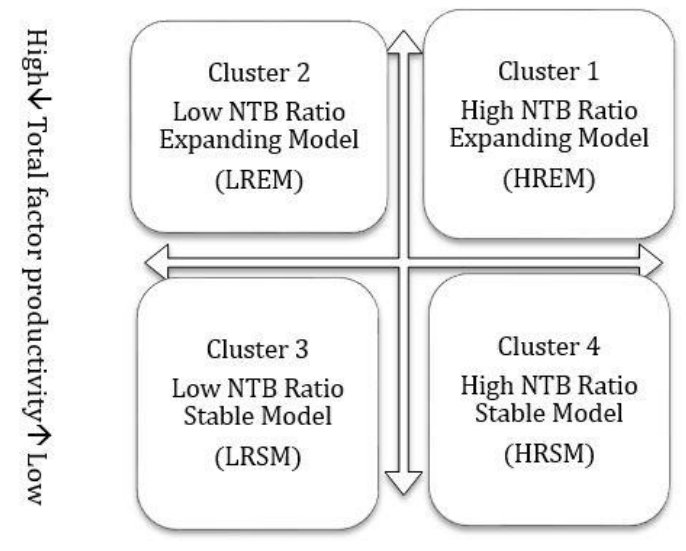

Low $\leftarrow$ Nurse-to-bed ratio $\rightarrow$ High

\section{Results}

According to the data collection and statistical analysis, we got table 3. It revealed that the standard deviation and the distribution range are quite large among the variable of inputs and outputs comparing with the average. The types of metropolitan areas and remote areas cause this difference. This is also our interest. We would like to know how the lack of medical resources especially nurse manpower of medical resources impacts the medical productivity in different administrative regions. So, we standardize the data, which composes of nurse manpower to total bed ratio. Table 4 shows the NTB ratio, an average of the NTB ratio and average of annual changes in every cities/counties of various scale. We found that large-scale cities, their NTB ratio are all above 0.5 and most of them 
are at the forefront. While there is 2 cities' NTB ratio below 0.5 , one is a medium-sized city, and the other one is a small city. Three scales of cities all can get the high average of annual change rate. That means to get the better medical resource and can lead to better medical output efficiency. It won't be the size of the city that inhibits the development of medical resource and so does medical output.

Table 5 summarizes the three MIs for the 22 counties and cities during the period 2005-2014. We calculated the annual average nurse-to-bed ratio and the average change in the nurse-to-bed ratio. The medical service industry averaged a $0.4 \%$ annual increase in EFFCH over the 10 -year period. The TC component largely offset gains in the EFFCH factor, which yielded a decrease in TFP of $1.3 \%$ each year (mean $=0.987$ ). The mean value of the average nurse-to-bed ratio in Taiwan was 0.632 during this period, and the mean value of annual changes in the average nurse-to-bed ratio was 1.020 , which translates into $2 \%$ average increase in nursing manpower each year. Our objective was to elucidate how changes in the three MIs correlate to NTB-A and NTB-AC. The scale of the city/county was shown to influence the three MIsas shown in Tables 6.

Table 6: The correlations between three MIs and NTB-A, NTB-AC in three scales of the cities/counties

\begin{tabular}{|c|c|c|c|c|c|c|}
\hline \multirow[b]{2}{*}{ Correlation } & \multicolumn{2}{|c|}{$\begin{array}{r}\text { Large beds capacity } \\
>10000\end{array}$} & \multicolumn{2}{|c|}{$\begin{array}{r}\text { Medium beds capacity } \\
1000-10,000\end{array}$} & \multicolumn{2}{|c|}{$\begin{array}{r}\text { Small beds capacity } \\
<1000\end{array}$} \\
\hline & NTB-A & NTB-AC & NTB-A & NTB-AC & NTB-A & NTB-AC \\
\hline $\mathrm{EC}$ & $-0.745^{*}$ & 0.680 & -0.153 & -0.378 & 0.823 & 0.936 \\
\hline $\mathrm{TC}$ & 0.414 & -0.528 & -0.059 & -0.426 & 0.180 & -0.063 \\
\hline TFP & -0.694 & 0.548 & -0.149 & $-0.660 * *$ & 0.426 & 0.194 \\
\hline Significance & NTB-A & NTB-AC & NTB-A & NTB-AC & NTB-A & NTB-AC \\
\hline $\mathrm{EC}$ & 0.045 & 0.069 & 0.309 & 0.101 & 0.193 & 0.115 \\
\hline $\mathrm{TC}$ & 0.207 & 0.141 & 0.424 & 0.073 & 0.442 & 0.480 \\
\hline TFP & 0.063 & 0.130 & 0.314 & 0.007 & 0.360 & 0.438 \\
\hline
\end{tabular}

As shown in Table 6, EFFCH was inversely proportional to NTB-A $(r=-0.745, p<0.05)$ in the large cities. This is an indication that a high nurse-to-bed ratio is generally related to low technical efficiency, as described by Farsi and Filippini (2005). TFP was inversely proportional to NTB-AC in medium-sized cities $(r=-0.66, p<0.01)$.

Figure 2: Scatter plot of TFP and NTB ratio in the 22 cities/counties

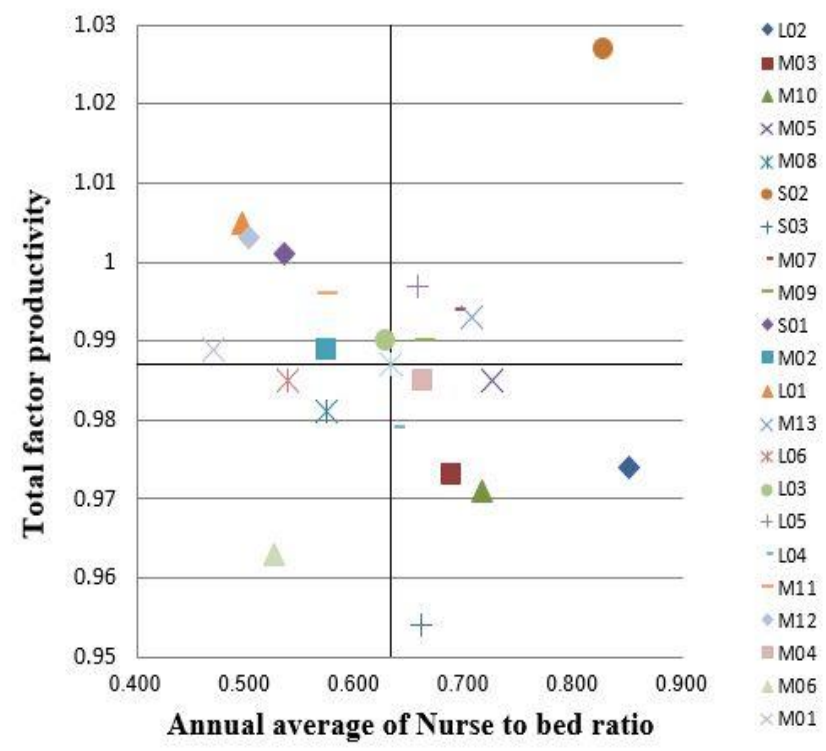

Figure 2 presents a scatter plot of TFP and NTB ratio in the 22 counties and cities examined in this study. The X and $Y$ axes respectively present the mean values of NTB ratio and TFP with the 22 cities divided into four quadrants. As shown in Table 5, the TFP and NTB ratio are higher in the first quadrant, indicating that the quality of medical care in that city gradually increased. Medium-sized municipalities, such as Taoyuan City and Miaoli County, fall into this group. The city with the best care was Kinmen County, located in the outer island region with manpower support from the Veterans General Hospital in Taipei. The second quadrant lists cities with high TFP and low NTB. These facilities appear to be well-managed, showing constant growth and an adequate level of efficiency. The seven cities in the fourth quadrant provide high-quality medical care but present a decline in TFP. According to the table 5, grouping principle and description above, we get the scatter plot as Figure 2 and classify the 22 
cities/counties into four groups as table 7.

Table 7: Classification of cities/counties according to performance

\begin{tabular}{llrrrrrrr}
\hline Groups & Types & & & & & & \multicolumn{2}{r}{ Samples } \\
\hline First quadrant & HREM & S02 & M07 & M09 & M13 & L05 & & \\
Second quadrant & LREM & S01 & M02 & L01 & L03 & M11 & M12 & M01 \\
Third quadrant & LRSM & M08 & L06 & M06 & & & & \\
Fourth quadrant & HRSM & L02 & M03 & M10 & M05 & S03 & L04 & M04 \\
\hline
\end{tabular}

\section{Conclusion and implications}

Hospital managers and physicians seek to improve the quality of care as well as productivity; however, balancing the two objectives can be difficult, particularly within a National Health Insurance system. Increased nurse manpower can improve access to medical services for relatively underserved populations(Barer, Wood, \& Schneider, 2014). Over the study period (2005-2014), hospital managers were shown to increase technical efficiency; however, they were unable to improve the underlying quality of care known as technological change. Overall, they decreased total factor productivity in Taiwan's medical service industry in the second decade of National Health Insurance. This means that TC accounted for a large proportion of the TFP. Increasing productivity first requires improvement of the underlying care processes. Technical efficiency can be improved by medical management measures such as decreased manpower and increased beds and examination equipment in short time. However, TC may be difficult to rationalize in terms of short-run return on investment and may be neglected. That is why we got lost of total factor productivity in the past decade. Increased qualified and registered nurse, improved underlying education process, elevated the motivation of willing to advocate to work and balancing the geographic distribution are the current workforce policies of our government. The conditions are the same as other medical staffs.

We also investigated the correlation between the three MIs and NTB ratio. In medium-sized cities, improvements in productivity were inversely related to increases in manpower. Improvements in productivity depended less on nursing manpower and more on efficiency where the number of beds is generally high. In this situation, nursing manpower can be controlled to improve efficiency.

As also we established four models for assessing the quality of care with a focus on productivity: high NTB ratio expanding model (HREM), low NTB ratio expanding model (LREM), low NTB ratio stable model (LRSM) and high NTB ratio stable model (HRSM). HREM refers to improvements in productivity based on high-quality care. Medium- to large-sized cities in more remote areas are included in this model. LREM refers to cases in which productivity was improved by controlling costs. Large urbanized cities, such as Taipei and Taichung, are included in this model. LRSM refers to cities that were unable to improve productivity despite controlling costs associated with nursing manpower. These areas require improvements in management skills. HRSM cities provide superior care without sacrificing productivity. These areas require improvements in efficiency strategies in order to become HREM. These models correspond to the current status of the medical service industry in Taiwan and can be extended to the same situation in National Health Insurance system and in the developing country. These four models cover the uneven development, and geographic distribution of the regions can provide the government policy makers the guidance in the development of strategies by which to improve productivity as well as the quality of care.

\section{References}

Association, A. N. (1997). Implementing nursing's report card: A study of RN staffing, length of stay, and patient outcomes: Amer Nurses Assn.

Association, A. N. (2000). Nurse staffing and patient outcomes in the inpatient hospital setting. Amer Nurses Assn.

Barer, M. L., Wood, L. C., \& Schneider, D. G. (2014). Toward improved access to medical services for relatively underserved populations: Canadian approaches, foreign lessons.

Barros, C. P., De Menezes, A. G., Peypoch, N., Solonandrasana, B., \& Vieira, J. C. (2008). An analysis of hospital efficiency and productivity growth using the Luenberger indicator. Health care management science, 11(4), 373-381.

Burke, D. E., \& Menachemi, N. (2004). Opening the black box: measuring hospital information technology capability. Health Care Management Review, 29(3), 207-217.

Conrad, D. A. (2009). Lessons to apply to national comprehensive healthcare reform. American Journal of Managed Care, 15(12), S306.

Färe, R., Grosskopf, S., Norris, M., \& Zhang, Z. (1994). Productivity growth, technical progress, and efficiency change 
in industrialized countries. The American economic review, 66-83.

Farsi, M., \& Filippini, M. (2005). An analysis of efficiency and productivity in Swiss hospitals: Università della Svizzera italiana.

Glickman, S. W., \& Peterson, E. D. (2009). Innovative health reform models: pay-for-performance initiatives. American Journal of Managed Care, 15(12), S300.

Harrison, M. I., Henriksen, K., \& Hughes, R. G. (2007). Improving the health care work environment: Implications for research, practice, and policy. The Joint Commission Journal on Quality and Patient Safety, 33(Supplement 1), 81-84.

Herr, A. (2008). Cost and technical efficiency of German hospitals: does ownership matter? Health Economics, 17(9), 1057-1071.

Malmquist, S. (1953). Index numbers and indifference surfaces. Trabajos de Estadistica y de Investigacion Operativa, 4(2), 209-242.

Mark, B. A., Harless, D. W., McCue, M., \& Xu, Y. (2004). A longitudinal examination of hospital registered nurse staffing and quality of care. Health Services Research, 39(2), 279-300.

Nadzam, D. M., \& Macklis, R. M. (2001). Promoting patient safety: is technology the solution? The Joint Commission Journal on Quality and Patient Safety, 27(8), 430-436.

Nishimizu, M., \& Page, J. M. (1982). Total factor productivity growth, technological progress and technical efficiency change: dimensions of productivity change in Yugoslavia, 1965-78. The Economic Journal, 92(368), 920-936.

Ozcan, Y. A. (2008). Health care benchmarking and performance evaluation. An assessment using data envelopment analysis (DEA).

Sikka, V., Luke, R. D., \& Ozcan, Y. A. (2009). The efficiency of hospital-based clusters: Evaluating system performance using data envelopment analysis. Health Care Management Review, 34(3), 251-261.

Singer, S. J., Falwell, A., Gaba, D. M., Meterko, M., Rosen, A., Hartmann, C. W., \& Baker, L. (2009). Identifying organizational cultures that promote patient safety. Health Care Management Review, 34(4), 300-311.

Tompkins, C. P., Higgins, A. R., \& Ritter, G. A. (2009). Measuring outcomes and efficiency in Medicare value-based purchasing. Health Affairs, 28(2), w251-w261. 